\title{
B-type natriuretic peptide is a biomarker for pulmonary hypertension in preterm infants with bronchopulmonary dysplasia
}

This article was published in the following Dove Press journal:

Research and Reports in Neonatology

3 May 2013

Number of times this article has been viewed

\author{
Alain Cuna' \\ Jegen Kandasamy' \\ Naomi Fineberg ${ }^{2}$ \\ Brian Sims ${ }^{\prime}$ \\ 'Department of Pediatrics, Division \\ of Neonatology, ${ }^{2}$ Department of \\ Biostatistics, University of Alabama \\ at Birmingham, Birmingham, AL, USA
}

Correspondence: Brian Sims Department of Pediatrics, Division of Neonatology, University of Alabama at Birmingham, 1700 6th Avenue South, Women and Infant's Center, Birmingham, AL 35249, USA

Tel +l 2059344680

$\mathrm{Fax}+\mathrm{I} 2059343100$

Email bsims@peds.uab.edu
Background: B-type natriuretic peptide (BNP) is a cardiac biomarker useful in screening for pulmonary hypertension $(\mathrm{PH})$ in adults. It is possible that BNP may also be useful in detecting $\mathrm{PH}$ among preterm infants with bronchopulmonary dysplasia (BPD).

Objective: To determine the utility of BNP for identification of $\mathrm{PH}$ among preterm infants with BPD

Methods: We retrospectively identified preterm infants with BPD who underwent screening echocardiography for suspected $\mathrm{PH}$ and had serum BNP levels measured within 10 days before or after echocardiography. Eligible infants were classified based on echocardiographic diagnosis of either PH or no PH. Median and interquartile ranges (IQR) of BNP values were compared, and area under the curve (AUC) of receiver operator characteristic (ROC) analysis was used to determine the optimum threshold value for detection of $\mathrm{PH}$.

Results: Twenty-five preterm infants with BPD (mean gestational age $26.5 \pm 1.7$ weeks, mean birth weight $747 \pm 248 \mathrm{~g}$ ) were identified. The median difference in days between echocardiography and BNP measurement was 1 day (IQR 0-3, range 0-10 days). Based on echocardiography, 16 were diagnosed with $\mathrm{PH}$ and nine without $\mathrm{PH}$. No significant difference in terms of gestational age, birth weight, sex, race, or respiratory support was found between the two groups. Median (IQR) BNP values of those with PH were higher than those without PH $(413$ [212-1178] pg/mL versus $55[21-84] \mathrm{pg} / \mathrm{mL}, P<0.001)$. AUC of ROC analysis showed that a BNP value of $117 \mathrm{pg} / \mathrm{mL}$ had $93.8 \%$ sensitivity and $100 \%$ specificity for detecting $\mathrm{PH}$.

Conclusion: BNP estimation may be useful for screening of PH in infants with BPD.

Keywords: B-type natriuretic peptide, pulmonary hypertension, bronchopulmonary dysplasia, biological markers, prematurity

\section{Introduction}

Pulmonary hypertension $(\mathrm{PH})$ is one of the most serious complications of bronchopulmonary dysplasia (BPD). ${ }^{1,2}$ Early detection of $\mathrm{PH}$ is important due to its association with significantly worse outcomes. ${ }^{3}$ However, diagnosis of PH among BPD infants is often delayed due to its subtle symptoms that overlap with respiratory symptoms of BPD itself. Though cardiac catheterization remains the gold standard for diagnosis, it is highly invasive and rarely done as the initial test. Echocardiography has thus become the preferred screening test of choice for PH. However, echocardiography is not always readily available at all institutions and has important limitations of its own. ${ }^{4}$ Measurement of B-type natriuretic peptide (BNP) has been found effective for the evaluation of patients with suspected $\mathrm{PH}$ in adults, ${ }^{5,6}$ and has been suggested to also be useful in screening infants with BPD for PH. ${ }^{7}$ There is very limited evidence 
however to support this. Thus, this current study aims to investigate the potential utility of BNP in screening for $\mathrm{PH}$ in preterm infants with BPD.

\section{Methods}

The following describes a retrospective study conducted at the Neonatal Intensive Care Units of University of Alabama at Birmingham and Children's of Alabama, Birmingham, AL, USA. Approval by the local ethics committee was obtained prior to the start of this study.

Extremely preterm infants admitted between September 2010 and August 2012 with BPD were identified from the neonatal database. BPD was diagnosed and graded at 36 weeks postmenstrual age ${ }^{8}$ using the physiologic definition for oxygen requirement. ${ }^{9}$ The infants' clinical charts were examined to identify those who: (1) underwent echocardiography as screening for suspected $\mathrm{PH}$ and (2) had serum BNP level measured within 10 days before or after echocardiography. Infants with structural heart defects other than a patent ductus arteriosus (PDA) or a patent foramen ovale, and those with multiple congenital anomalies were excluded.

Eligible infants were categorized according to $\mathrm{PH}$ based on screening echocardiography results. Echocardiograms were performed by certified technicians and read by board certified pediatric cardiologists. All echocardiograms were performed using Sonos 500 ultrasound machine (Philips Healthcare, Andover, MA, USA). Infants were diagnosed with $\mathrm{PH}$ if at least one of the following echocardiographic findings was present: (1) elevated tricuspid regurgitation jet velocity, (2) interventricular septum flattening, (3) right ventricular hypertrophy, or (4) right to left shunting. Data on corresponding serum BNP levels obtained within 10 days of echocardiography were collected. Baseline demographic data and respiratory support at the time of echocardiography were also recorded.

Data were expressed as a median and interquartile range (IQR), mean and standard deviation, or counts and percentage. Association between $\mathrm{PH}$ diagnosis and categorical values (sex, race, respiratory support, PDA, BPD) was assessed using Fisher's exact test. For continuous variables (gestational age, birth weight, age at screening, BNP), $t$-test or Mann-Whitney $U$ test was used. Area under the receiver-operating characteristic (ROC) curve was computed and optimal cutoff value of BNP for PH diagnosis was established. Log transformation of BNP values to normalize data was also done, and univariate analysis of covariance performed to determine relationship of BNP with PH after controlling for other covariables. A twosided $P<0.05$ was considered statistically significant.

\section{Results}

Twenty-five preterm infants with BPD were identified to have undergone screening echocardiography for $\mathrm{PH}$ and also had serum BNP level obtained within 10 days. Mean gestational age was $26.5 \pm 1.7$ weeks and mean birth weight was $747 \pm 248 \mathrm{~g}$. The median number of days between echocardiography and serum BNP measurement was 1 day (IQR 0 to 3 days, range 0 to 10 days). Sixteen of the infants had $\mathrm{PH}$ and nine had no PH on echocardiography. Characteristics of the study participants are shown in Table 1.

Patients with PH were noted to be older at time of screening (104 \pm 34 days versus $77 \pm 59$ days, $P=0.03)$ and have higher median BNP values [413 [212-1178] pg/mL versus 55 [21-84] pg/mL, $P<0.001]$. The other demographics and general findings were otherwise similar between the two groups. After controlling for baseline variables, BNP maintained independent predictive ability for PH $(P<0.001)$. Area under the ROC curve for BNP to diagnose PH was 0.993, with an identified optimal cutoff value of $117 \mathrm{pg} / \mathrm{mL}$. Using this cutoff, BNP showed a sensitivity of $93.8 \%$ and a specificity of $100 \%$ for diagnosing $\mathrm{PH}$.

\section{Discussion}

This study broadens the possible application of BNP in neonates to include screening of preterm infants with BPD for PH. Specifically, our results show that an elevated BNP level of $>117 \mathrm{pg} / \mathrm{mL}$ obtained around the time of screening echocardiography correlated with echocardiographic detection of $\mathrm{PH}$ among preterm BPD infants. Our results are consistent with other investigators who have also shown similar utility of BNP as a diagnostic biomarker in neonates with congenital heart disease, ${ }^{10}$ hemodynamically significant PDA,,${ }^{11,12}$ and persistent PH of the newborn. ${ }^{13,14}$ Given the limitations of both cardiac catheterization and echocardiography especially in preterm infants, ${ }^{4}$ BNP could be an attractive adjunct for screening of $\mathrm{PH}$ that is noninvasive, cost-effective, and readily available.

In this study, we did not exclude infants with PDA from analysis. It is possible that the presence of PDA in some of the study infants $(n=6)$ may have contributed to higher BNP levels. ${ }^{15}$ However, analysis of covariance confirmed that BNP maintained its strong relationship with PH despite controlling for other variables including PDA. It is also important to note the lack of data on renal function at the time of BNP measurement, as renal dysfunction can also contribute to higher BNP levels. ${ }^{16,17}$ However, no infant in the study had clinical suspicion of renal dysfunction (poor urine output, unstable electrolytes, rising creatinine) at the time of BNP measurement. 
Table I Baseline characteristics of all BPD infants and comparison between those with and without PH

\begin{tabular}{|c|c|c|c|c|}
\hline Characteristic & All BPD & BPD with PH & BPD without PH & $P$-value \\
\hline Patients, $\mathrm{n}$ & 25 & 16 & 9 & \\
\hline Gestational age, weeks & $26.45 \pm 1.7$ & $26.48 \pm 1.9$ & $26.38 \pm 1.2$ & 0.89 \\
\hline Birth weight, $g$ & $747.16 \pm 248$ & $731.19 \pm 298$ & $775.56 \pm 130.74$ & 0.14 \\
\hline Male/female & $17 / 8$ & $12 / 4$ & $5 / 4$ & 0.39 \\
\hline Race & & & & 1.0 \\
\hline AA & II (44\%) & 7 (43.8\%) & 4 (44.4\%) & \\
\hline $\mathrm{C}$ & 14 (56\%) & $9(56.2 \%)$ & $5(55.6 \%)$ & \\
\hline Age at screening, days & $94 \pm 45$ & $104 \pm 34$ & $77 \pm 59$ & 0.03 \\
\hline Respiratory support & & & & 0.93 \\
\hline $\mathrm{NC}$ & $7(28 \%)$ & $4(25 \%)$ & $3(33.3 \%)$ & \\
\hline CPAP & $5(20 \%)$ & $4(25 \%)$ & I (II.I\%) & \\
\hline Ventilator & $13(52 \%)$ & $8(50 \%)$ & $5(55.6 \%)$ & \\
\hline BPD & & & & 0.817 \\
\hline Mild & $2(8 \%)$ & I (6\%) & I (II\%) & \\
\hline Moderate & $2(8 \%)$ & I (6\%) & I (II\%) & \\
\hline Severe & $21(84 \%)$ & 14 (88\%) & 7 (78\%) & \\
\hline PDA & $6(24 \%)$ & $2(12.5 \%)$ & $4(44.4 \%)$ & 0.142 \\
\hline BNP, pg/mL & $211(74,854)$ & $4 \mid 3(2|2| 178)$, & $55(21,84)$ & $<0.001$ \\
\hline
\end{tabular}

Note: Data are expressed as mean $\pm \mathrm{SD}$, as number (percentage), or as median (IQR).

Abbreviations: AA, African American; BNP, B-type natriuretic peptide; BPD, bronchopulmonary dysplasia; C, Caucasian; CPAP, continuous positive airway pressure; $\mathrm{IQR}$, interquartile range; NC, nasal cannula; PDA, patent ductus arteriosus; $\mathrm{PH}$, pulmonary hypertension, SD, standard deviation.

A more subtle limitation is the use of echocardiography in determining PH. Though echocardiography is commonly performed as the initial test for detecting $\mathrm{PH}$, it remains a screening test with important limitations. ${ }^{4}$ Ideally, a diagnostic biomarker under consideration would be compared with the gold standard, which in the case of PH is cardiac catheterization. However, cardiac catheterization is highly invasive and rarely done especially in premature infants with significant lung disease.

It is interesting to note that BPD infants with $\mathrm{PH}$ were older than those without $\mathrm{PH}$. Whether older postnatal age contributed to higher BNP levels among preterm BPD infants with PH is unknown. However studies in both term and preterm infants consistently showed that BNP levels are highest during the first few days of life and decrease with increasing age. ${ }^{18,19} \mathrm{~A}$ more plausible reason is that majority of $\mathrm{PH}$ among preterm BPD infants is diagnosed at a later age. This is consistent with a recent prospective study where screening echocardiography of extremely low birth weight infants at 4-6 weeks of age detected only one-third of infants who subsequently develop PH. The remaining two-thirds were detected to have PH later on at 3 to 4 months of age. ${ }^{20}$

It is also important to note the high number (64\%) of preterm BPD infants with $\mathrm{PH}$ in our study. This is in contrast to previous retrospective studies that estimated the incidence of PH from $25 \%-37 \%$ of infants with BPD. ${ }^{21,22}$ This was most likely due to selection bias, as only preterm BPD infants who were at especially high risk for having
PH (extremely premature, extremely low birth weight, with significant respiratory support) were screened with echocardiography. In addition, not all infants who had screening echocardiography for $\mathrm{PH}$ were included in the study due to lack of corresponding BNP level drawn.

Major limitations of our study remain the small number of patients included and its retrospective nature. A prospective study involving a larger sample size is needed to further determine the usefulness of BNP as a screening tool for PH in preterm infants. Other questions that need to be answered include whether BNP can also be used to follow the course of PH. Specifically, to determine whether BNP values decrease with treatment and resolution of $\mathrm{PH}$ and increase with worsening of PH. Also, it would be important to know whether high BNP values correlate with worse clinical status and other important clinical outcomes including length of stay and mortality.

\section{Disclosure}

The authors report no conflicts of interest in this work.

\section{References}

1. Hislop AA, Haworth SG. Pulmonary vascular damage and the development of cor pulmonale following hyaline membrane disease. Pediatr Pulmonol. 1990;9(3):152-161.

2. Goodman G, Perkin RM, Anas NG, Sperling DR, Hicks DA, Rowen M. Pulmonary hypertension in infants with bronchopulmonary dysplasia. J Pediatr. 1988;112(1):67-72.

3. Kumar VH, Hutchison AA, Lakshminrusimha S, Morin FC, Wynn RJ, Ryan RM. Characteristics of pulmonary hypertension in preterm neonates. J Perinatol. 2007;27(4):214-219. 
4. Mourani PM, Sontag MK, Younoszai A, Ivy DD, Abman SH. Clinical utility of echocardiography for the diagnosis and management of pulmonary vascular disease in young children with chronic lung disease. Pediatrics. 2008;121(2):317-325.

5. Levin ER, Gardner DG, Samson WK. Natriuretic peptides. $N$ Engl J Med. 1998;339(5):321-328.

6. de Lemos JA, McGuire DK, Drazner MH. B-type natriuretic peptide in cardiovascular disease. Lancet. 2003;362(9380):316-322.

7. Kim GB. Pulmonary hypertension in infants with bronchopulmonary dysplasia. Korean J Pediatr. 2010;53(6):688-693.

8. Jobe AH, Bancalari E. Bronchopulmonary dysplasia. Am J Respir Crit Care Med. 2001;163(7):1723-1729.

9. Walsh MC, Yao Q, Gettner P, et al. Impact of a physiologic definition on bronchopulmonary dysplasia rates. Pediatrics. 2004;114(5): 1305-1311.

10. Maher KO, Reed H, Cuadrado A, et al. B-type natriuretic peptide in the emergency diagnosis of critical heart disease in children. Pediatrics. 2008;121(6):e1484-e1488.

11. Choi BM, Lee KH, Eun BL, et al. Utility of rapid B-type natriuretic peptide assay for diagnosis of symptomatic patent ductus arteriosus in preterm infants. Pediatrics. 2005;115(3):e255-e261.

12. Flynn PA, da Graca RL, Auld PA, Nesin M, Kleinman CS. The use of a bedside assay for plasma B-type natriuretic peptide as a biomarker in the management of patent ductus arteriosus in premature neonates. J Pediatr. 2005;147(1):38-42.

13. Reynolds EW, Ellington JG, Vranicar M, Bada HS. Brain-type natriuretic peptide in the diagnosis and management of persistent pulmonary hypertension of the newborn. Pediatrics. 2004;114(5):1297-1304.

14. Vijlbrief DC, Benders MJ, Kemperman H, van Bel F, de Vries WB. B-type natriuretic peptide and rebound during treatment for persistent pulmonary hypertension. J Pediatr. 2012;160(1):111-115. e111.
15. Puddy VF, Amirmansour C, Williams AF, Singer DR. Plasma brain natriuretic peptide as a predictor of haemodynamically significant patent ductus arteriosus in preterm infants. Clin Sci (Lond). 2002;103(1):75-77.

16. deFilippi CR, Seliger SL, Maynard S, Christenson RH. Impact of renal disease on natriuretic peptide testing for diagnosing decompensated heart failure and predicting mortality. Clini Chem . 2007;53(8):1511-1519.

17. McCullough PA, Duc P, Omland T, et al. B-type natriuretic peptide and renal function in the diagnosis of heart failure: an analysis from the Breathing Not Properly Multinational Study. Am J Kidney Dis. 2003;41(3):571-579.

18. Nir A, Bar-Oz B, Perles Z, Brooks R, Korach A, Rein AJ. N-terminal pro-B-type natriuretic peptide: reference plasma levels from birth to adolescence. Elevated levels at birth and in infants and children with heart diseases. Acta Paediatr. 2004;93(5):603-607.

19. Nir A, Lindinger A, Rauh M, et al. NT-pro-B-type natriuretic peptide in infants and children: reference values based on combined data from four studies. Pediatr Cardiol. 2009;30(1):3-8.

20. Bhat R, Salas AA, Foster C, Carlo WA, Ambalavanan N. Prospective analysis of pulmonary hypertension in extremely low birth weight infants. Pediatrics. 2012;129(3):e682-e689.

21. An HS, Bae EJ, Kim GB, et al. Pulmonary hypertension in preterm infants with bronchopulmonary dysplasia. Korean Circ J. 2010;40(3):131-136.

22. Slaughter JL, Pakrashi T, Jones DE, South AP, Shah TA. Echocardiographic detection of pulmonary hypertension in extremely low birth weight infants with bronchopulmonary dysplasia requiring prolonged positive pressure ventilation. J Perinatol. 2011;31(10):635-640.
Research and Reports in Neonatology

\section{Publish your work in this journal}

Research and Reports in Neonatology is an international, peer-reviewed, open access journal publishing original research, reports, editorials, reviews and commentaries on neonatal health. The manuscript management system is completely online and includes a very quick and fair
Dovepress

peer-review system. Visit http://www.dovepress.com/testimonials.php to read real quotes from published authors. 